\title{
Doctor for Society: paying tribute to role models of humanitarianism and professionalism
}

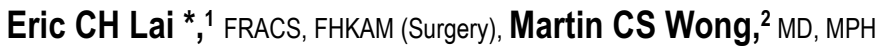 \\ ${ }^{1}$ Senior Editor, ${ }^{2}$ Editor-in-Chief \\ Hong Kong Medical Journal \\ * Corresponding author: laiericch@yahoo.com.hk
}

\begin{tabular}{l} 
Hong Kong Med J 2017;23:432 \\
\hline DOI: 10.12809/hkmj175071
\end{tabular}

The Doctor for Society section of the Hong Kong Medical Journal celebrates its fifth anniversary since its inception in 2012. Over 30 outstanding doctors have received interviews from our student reporters. Their career and community services are role models for our young generation. The Editorial Board would like to express our sincere gratitude and appreciation for their extremely elegant work and achievements that are to be celebrated.

The main objective of this section is to give our readers a better understanding of the activities and achievements of these medical doctors who contribute substantially and voluntarily to our society. ${ }^{1}$ Some perform humanitarian work in the society outside their clinics and hospitals, whilst others propagate advocacy groups on health issues, and help disseminate information to the needy via their selfless initiatives. Their stories tell us that doctors play a crucial role in various life-changing missions, ranging from providing care to disaster victims, training medical personnel in the developing world, to offering services to the less fortunate.

Our first interviewee featured in the August 2012 issue was Dr Nim-chung Chan, an experienced and dedicated ophthalmologist who worked in Afghanistan for more than 6 years for humanitarian causes. Other outstanding young ophthalmologists, such as Dr Emmy Li and Dr David Liu, have impressed readers with their unconditional service for the underprivileged. Dr Vivian Wong Taam evolved the health care paradigms; Dr Chungping Yu, Dr Patricia Ip, and Dr Fai-to Yau relieved the suffering of numerous children; Prof Faith Ho safeguarded cultural heritage; Dr William Wong promoted holistic primary care; Dr Judith Mackay, Dr Sin-ping Mak, and Dr Ben Cheung fight against the harm of tobacco, ${ }^{2}$ alcohol, ${ }^{3}$ and substance abuse, ${ }^{4}$ respectively; Dr Vincent Leung and Dr KL Cheung brought forth a system redesigned for humanitarian aid; Dr Chin-hung Chung and Dr Ho-yin Chung rolemodelled the service scope ${ }^{5}$ and public education, ${ }^{6}$ respectively, for emergency medicine; Dr Philip Ben protected women's rights and dignity; the list goes on. This will be the 32nd issue after the first interviewee, and features the community services organised and led by Prof Philip Chiu as an academic professor who actively pioneers research and provides training in minimally invasive surgery. ${ }^{7}$ A very prominent feature of Prof Chiu's achievements includes his services via painting in his various co-exhibitions with professional artists. His story conveys one important message to readers: the impact of medical doctors in society can be far reaching, beyond the professional field of medicine; this is an example of our colleagues who are prepared to give themselves to community service.

The Editorial Board looks forward to more eyeopening reports about our doctors, particularly about those who provide outstanding services beyond the realms of the medical and health sector. This will reflect more extensive participation of volunteers in our medical community. Our society needs a strong force of volunteers to serve in different places to hold our community together. They are our silent heroes, and it is time for us to applaud the improvements that have stemmed from their unstinting efforts. We hope that this series of articles will continue to convey the broader influence of medical doctors in society-beyond saving lives, prescribing drugs, and improving well-being in their work environment.

\section{References}

1. Wong M, Chan KS, Chu LW, Wong TW. Doctor for Society: a corner to showcase exemplary models and promote volunteerism. Hong Kong Med J 2012;18:268-9.

2. Chiba Z, Eu KS, Tam E. From the fringes of public health to the forefront of the fight against tobacco: Dr Judith Mackay. Hong Kong Med J 2016;22:88-9.

3. Yiu RS, Ho SS. Behind the silver plaque...the never-ceasing passion: an interview with Dr Sin-ping Mak. Hong Kong Med J 2016;22:626-7.

4. Ho S, Wong C. Expect the unexpected: an interview with Dr Ben Kin-leung Cheung. Hong Kong Med J 2016;22:2967.

5. Chan AY, Hui RW. Bringing emergency care into the community: an interview with Dr Chin-hung Chung. Hong Kong Med J 2016;22:400-1.

6. Cheuk NK, Yeung $\mathrm{CH}$. Investigating the investigator: probing into the life of the "Sherlock Holmes of the AED"... and more? An interview with Andrew Ho-yin Chung. Hong Kong Med J 2017;23:208-10.

7. Hui RW, Liu AQ, Wu AC. The scalpel and the brush: an interview with Professor Philip Wai-yan Chiu. Hong Kong Med J 2017;23:543-4. 